\title{
PENERAPAN METODE TECHOLOGY ACCEPTANCE MODEL PADA PENILAIAN KINERJA KARYAWAN
}

\author{
Sri Utami \\ Sistem Informasi \\ Universitas Bina Sarana Informatika \\ www.bsi.ac.id \\ Sri.sut@bsi.ac.id
}

\begin{abstract}
Technology Acceptance Model (TAM) is a model that can define the extent of perceived usefulness. With the TAM method is expected to provide evidence that employee performance can be good one of the factors is influenced by the leadership style where the employee shelter. Researchers conducted data collection using a research instrument in the form of a questionnaire by distributing 50 questionnaires to PT. Indonesia Super Holiday, consists of managers, supervisors, customer service, marketing and office boys, which is engaged in traveling where daily activities require good cooperation. From the test results, researchers get the significance of the influence of leadership style on employee performance. So hopefully in the future it can be a reference for leaders and employees to collaborate for the progress of the company. Leaders can maintain quality and even improve it and share knowledge with employees so that all work that is their responsibility can be completed with maximum results.
\end{abstract}

Keywords: Technology Acceptance Model, employee, performance, leader

Intisari- TAM merupakan suatu model yang bisa mendefenisikan sejauh mana persepsi kemanfaatan. Manfaat menilai kinerja karyawan memang penting dan rutin dilaksanakan, disayangkan evaluasi penilaiannya hanya melihat dari faktor karyawan itu sendiri. Dengan metode TAM diharapkan dapat memberikan pembuktian bahwa kinerja karyawan bisa baik salah satu faktor dipengaruhi oleh gaya kepemimpinan ditempat karyawan tersebut bernaung. Sehingga diharapkan kedepannya bisa menjadi acuan untuk pimpinan dan karyawan untuk bisa berkolaborasi demi kemajuan perusahaan. Pemimpin bisa mempertahankan kualitas bahkan meningkatkannya dan membagi ilmu kepada karyawan agar semua pekerjaan yang menjadi tanggungjawabnya bisa terselesaikan dengan hasil yang maksimal. Dari hasil penelitian strategi membangun kedekatan antara pimpinan dan bawahan memberi dampak positif terhadap kinerja karyawan. Hasil penelitian menunjukkan bahwa terdapat hubungan yang signifikan antara gaya kepemimpinan terhadap kinerja pegawai pada PT. Indonesia Super Holiday sebesar 0,877 dan termasuk dalam katagori sangat kuat

Kata Kunci: TAM, Karyawan, kinerja,Pemimpin.

\section{PENDAHULUAN}

Paradigma kinerja karyawan pada umumnya dilihat dari latar belakang pendidikan, meski belum diketahui seberapa baik hasil pekerjaannya saat keilmuannya diimplementasikan ke dunia kerja. Hal ini yang membuat kebanyakan orang lupa, peranan seorang pemimpin dalam mengarahkan karyawan baik yang sudah lama bekerja atau baru memulai sangat diperlukan (Surpiyanto, 2012).

Kepemimpinan yang paling berpengaruh terhadap kinerja pegawai dimana pimpinan melibatkan bawahannya dalam mengambil keputusan, pemimpin memberi keteladanan yang baik terhadap bawahan, dan pemimpin memberi plihan pemecahan masalah yang belum ada aturannya, seorang pemimpin perlu memberikan dorongan kepada bawahannya untuk melakukan inovasi dalam bekerja (Eva JR, 2015).

Menurut Prof. Dr. Deddy Mulyadi, Drs., M.Si (Mulyadi, 2015) kepemimpinan adalah kemampuan yang dimiliki seseorang dalam melaksanakan perannya untuk mempengaruhi suatu organisai untuk mencapai visi misi yang telah direncanakan. Sedangkan menurut Stephen P. Robbins dan Timothy A. Judge (Stephen P. Robbins \& Judge, 2015) ada empat teori kepemimpinan, yaitu:

1. Teori Sifat yaitu menjelaskan perbedaan yang bukan pemimpin dari para pemimpin yang dapat terlihat dari kualitas dan karakteristik setiap personalnya.

2. Teori perilaku kepemimpinan yang mengusulkan bahwa terdapat perilaku spesifik yang membedakan para pemimpin dari yang bukan pemimpin.

3. Teori Kontingensi 
4. Teori pertukaran pemimpin-anggota yang mendukung penciptaan para pemimpin di dalam kelompok dan di luar kelompok dengan status peringkat kinerja yang lebih tinggi.

Jadi dapat disimpulkan bahwa kepemimpinan merupakan suatu integritas yang dimiliki seseorang untuk dapat memberikan pengaruh dari kemampuan yang dimilikinya berupa memberi arahan dan mengawasi bawahannya untuk dapat mengerjakan tugas sejalan dengan tujuan dari organisasi yang ingin dicapai.

Gaya kepemimpinan menurut Prof. Dr. Deddy Mulyadi, Drs., M.Si (Mulyadi, 2015) ada tiga macam gaya, yang pertama Gaya Otokratis merupakan sikap dari seorang pemimpin dijadikan panutan oleh pengikutnya, menjelaskan tugas setiap pekerjaan dan memberi arahan mengenai kedisiplinan waktu dalam menyelesaikan tugas kepada pengikutnya. Kedua, gaya demokratis adalah seorang pemimpin merangkul pengikutnya dalam mencari solusi dari suatu permasalahan, memberi keleluasaan pengikutnya untuk bekerja dengan siapapun kelompoknya, dan bisa objektif terhadap pengikutnya. Ketiga, kebebasan sikap seorang pemimpin yang bisa memberi arahan saat pengikutnya mengalami kesulitan, dimana keputusan tetap diserahkan kepada pengikutnya, tidak ada peran serta dari seorang pemimpin dalam menentukan tugas pengikut dan memberikan respon secara realtime kepada pengikutnya dengan tidak memiliki maksud dan tujuan tertentu.

Dengan adanya gaya kepemimpinan memberikan dampak bagi suatu organisasi sehingga terciptanya suasana kerja yang kondusif, memberikan dampak semangat dan efektivitas kerja kepada pengikutnya. Namun jika seorang pemimpin tidak memiliki jiwa kepimpinan maka akan memberi pengaruh negatif bagi kelangsungan suatu organisasi. Menurut Hamsinah, Herman Sjahruddin dan Mustafa Gani (Hamsinah, Sjahruddin, \& Gani, 2017) bahwa adanya seorang pemimpin diharapkan pengikut dapat mencapai keberhasilan aktivitas kerja, perilaku dan prestasi bawahannya yang selaras dengan perintah atas ketentuan organisasi.

Kriteria untuk menilai kinerja pegawai menurut Asri Laksmi Riani (Riani, 2013), ada 6 yaitu:

1. Quality

Merupakan hasil kerja keras dari para karyawan yang sesuai dengan tujuan yang telah ditetapkan oleh pihak perusahaan sebelumnya. Jika hasil yang dicapai oleh karyawan tersebut tinggi maka kinerja dari karyawan tersebut dianggap baik oleh pihak perusahaan atau sesuai dengan tujuannya. Ini berarti merupakan suatu tingkatan yang menunjukkan proses pekerjaan atau hasil yang dicapai atas suatu pekerjaan mendekati adanya kesempurnaan.

2. Quantity

Quantity merupakan jumlah yang diproduksi yang dinyatakan dalam nilai mata uang, jumlah unit produksi ataupun dalam jumlah siklus aktivitas yang telah terselesaikan.

3. Timeliness

Hal ini menyangkut ketepatan waktu penyelesaian pekerjaan. Dimana aktivitas dapat diselesaikan dengan waktu yang lebih cepat dari yang telah ditentukan dan memaksimalkan waktu yang ada untuk aktivitas yang lain.

4. Cost Effectiveness

Cost effectiveness merupakan suatu tingkatan yang paling maksimal dari penggunaan sumber daya (manusia, keuangan, teknologi) yang dimiliki perusahaan untuk mendapatkan keuntungan yang maksimal atau mengurangi kerugian dari masing-masing unit atau sebagai pengganti dari penggunaan sumber daya.

5. Need For Supervisor

Need for supervision merupakan suatu tingkatan di mana seseorang karyawan dapat melaksanakan suatu fungsi pekerjaan tanpa harus meminta bimbingan atau campur tangan dari pimpinan.

6. Interpersonal Impact

Merupakan suatu tingkatan keadaan di mana karyawan dapat menciptakan suasana nyaman dalam bekerja, percaya diri, berbuat baik dan kerjasama antar rekan sekerja.

Technology Acceptance Model (TAM) merupakan salah satu model yang dirancang untuk menganalisis dan mempengaruhi faktor, faktor yang memperngaruhi diterimanya penggunaan teknologi komputer (Davis, 1986). TAM bertujuan untuk menerangkan dan memprediksi penerimaan pengguna terhadap suatu sistem informasi. TAM menyediakan suatu basis teoritis untuk menganalisa diantara keyakinan dan perilaku, dari penggunaan aktual dari pengguna suatu sistem informasi.

Manfaat Technology Acceptance Model (Wijaya, 2006) :

1. Penggunaan teknologi dapat meningkatkan produktivitas pengguna

2. Pengguaan teknologi dapat meningkatkan kinerja pengguna

3. Penggunaan teknologi dapat meningkatkan efisiensi proses yang dilakkukan pengguna. 
Karyawan seperti seorang anak yang butuh figur untuk dijadikan panutan, figur dalam suatu organisasi atau perusahaan adalah pimpinan. Untuk memberikan keyakinan atas seberapa besar faktor figur terhadap kinerja karyawan, peneliti menggunakan Technology Acceptance Model (TAM). TAM merupakan suatu model yang bisa medefinisikan sejauh mana persepsi kemanfaatan. Hal ini menjadi bahan pertimbangan bagi peneliti untuk menganalisa seberapa pengaruh seorang pemimpin dilihat dari Gaya Kepemimpinannya terhadap kinerja karyawan menggunakan metode TAM.

\section{BAHAN DAN METODE}

Penelitian ini menggunakan riset pengujian hipotesis dan analisa deskriptif untuk memperoleh data yang valid di dalam menafsirkan data dengan metode TAM. Data dikumpulkan dengan metode sebagai berikut:

1. Observasi

2. Penyebaran kuesioner

3. Studi pustaka digunakan untuk mendapatkan informasi yang dibutuhkan dan menunjang penelitian melalui jurnal dari penelitian terdahulu, buku referensi.

\section{Variabel Penelitian}

Penelitian ini menggunakan dua variabel yaitu variabel bebas Gaya Kepemimpinan (X) dan variabel terikat Kinerja Karyawan (Y). Dengan Populasi sebanyak 50 orang karyawan. Kuesioner diberikan langsung sehingga peneliti dapat memberikan penjelasan mengenai tujuan penelitian dan cara pengisian kuesioner kepada responden. Pertanyaan-pertanyaan pada kuesioner menggunakan skala likert.

Tabel 1. Skala Likert

\begin{tabular}{|l|c|}
\hline \multicolumn{1}{|c|}{ Jawaban } & Skor \\
\hline Sangat Setuju & 5 \\
\hline Setuju & 4 \\
\hline Cukup Setuju & 3 \\
\hline Tidak Setuju & 2 \\
\hline Sangat Tidak Setuju & 1 \\
\hline
\end{tabular}

\section{HASIL DAN PEMBAHASAN}

\section{Uji Validitas}

Tabel 2. Hasil Uji Validitas

\begin{tabular}{|ll|l|l|}
\hline & $\mathrm{X}$ & $\mathrm{Y}$ \\
\hline $\mathrm{X}$ & Pearson Correlation & 1 & $.877^{* *}$ \\
Sig. (2-tailed) & & .000 \\
$\mathrm{~N}$ & 50 & 50 \\
\hline
\end{tabular}

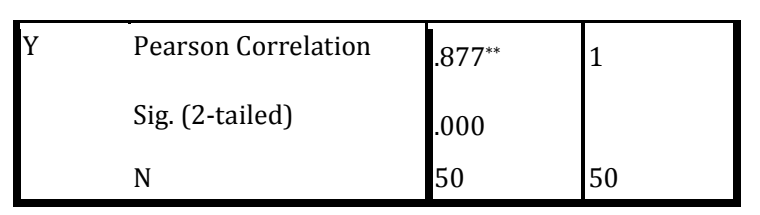

Sumber: olah data (2019)

(Ho): Tidak terdapat pengaruh Gaya Kepemimpinan terhadap Kinerja Karyawan $\left(\mathrm{H}_{1}\right)$ : Terdapat Pengaruh Gaya Kepemimpinan terhadap Kinerja Karyawan

Hasil yang diperoleh menunjukkan bahwa nilai $\mathrm{t}$ dari pengaruh Gaya Kepemimpinan terhadap Kinerja Karyawan sebesar 12.662, dengan $\beta=$ 0.887 dan tingkat signifikansi 0.000 ( $\mathrm{p}<0.05$ ) yang berarti Ho ditolak dan $\mathrm{H}_{1}$ diterima, sehingga benar terdapat pengaruh Gaya Kepemimpinan terhadap Kinerja Karyawan di perusahaan.

\section{Uji Reliabilitas}

Uji reliabilitas merupakan suatu cara untuk mengukur suatu kuesioner yang terbentuk dari indikator dan variabel. Suatu kuesioner dapat dinyatakan reliabitas apabila jawaban dari responden terhadap pertanyaan bersifat konsisten dari waktu ke waktu dan nilai cronbach's alpha lebih dari 0.6.

Tabel 3. Hasil Uji Reliabilitas

\begin{tabular}{|l|l|}
\hline $\begin{array}{l}\text { Cronbach's } \\
\text { Alpha }\end{array}$ & N of Items \\
\hline 933 & 2 \\
\hline
\end{tabular}

Sumber: Olah data (2019)

Dapat dibuktikan bahwa variabel Gaya Kepemimpinan dan Kinerja Karyawan nilai conbrach's alpha sebesar 0,933 lebih dari 0.6, maka kedua variabel dapat membuktikan konsisten.

\section{Uji Asumsi Klasik}

Untuk menyempurnakan hasil uji model regresi, peneliti melakukan pengujian normalitas, uji multikolinearitas dan uji autokorelasi.

\section{Uji Normalitas}

Uji normalitas dilakukan agar mengetahui normal atau tidak model regresi terdistribusi. Untuk mendeteksi kenormalan dapat dilihat dari data yang menyebar disekitar garis diagonal dan mengikuti arah diagonal. Maka model regresi memenuhi asumsi normalitas. 


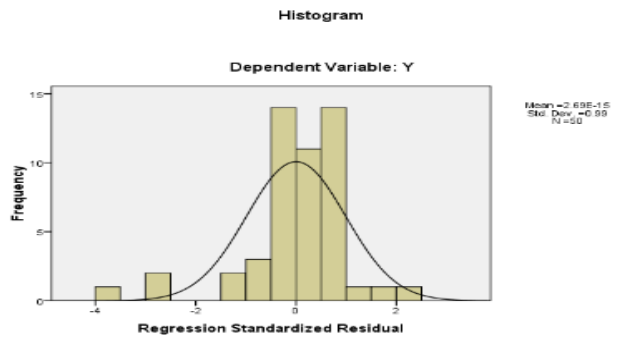

Gambar 1. Hasil Uji Normalitas

Melihat pola distribusi pada grafik membuktikan model regresi layak untuk dipakai karena memenuhi asumsi normalitas. Jika terdapat koefisien yang bernilai negatif atau yang tidak signifikan apabila nilai $p$ tersebut memiliki angka 0,05 (Utami, 2017).

\section{Uji Multikolinearitas}

Uji multikolinearitas digunakan untuk mengetahui ada tidaknya korelasi antar variabel independen. (Priyatno, 2012) Pada model regresi yang baik seharusnya tidak terjadi korelasi yang sempurna atau mendekati sempurna di antara variabel bebas.

Tabel 4. Hasil Uji Multikolinearitas

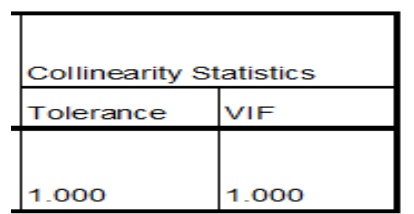

Dalam ketetapan bahwa tidak terjadi multikolinieritas jika Tolerance lebih dari 0.1 dan VIF (Variance Inflation Factor ) kurang dari 10. Maka berdasarkan nilai yang diperoleh nilai VIF = 1 dapat disimpulkan tidak ditemui masalah multikolonieritas antar variabel bebas.

\section{Uji Autokorelasi}

Pengujian autokorelasi bermaksud agar data yang diteliti dapat diketahui terjadi korelasi atau tidak.

Tabel 5. Hasil Uji Autokorelasi

\begin{tabular}{|l|l|l|l|l|}
\hline Model & $\mathrm{R}$ & R Square & $\begin{array}{l}\text { Adjusted R } \\
\text { Square }\end{array}$ & $\begin{array}{l}\text { Std. Error of } \\
\text { the Estimate }\end{array}$ \\
\hline 1 & $.877^{\mathrm{a}}$ & .770 & .765 & .246 \\
\hline
\end{tabular}

Dari Hasil yang diperoleh nilai korelasi mendekati angka 1 yaitu 0,877 yang berarti terjadi hubungan yang sangat erat antar variabel. Hal ini dapat diperkuat dari nilai koefisien determinasi sebesar 77,0\% dan nilai adjusted $\mathrm{R}$ square sebesar 0,765 yang menunjukkan persentase sumbangan pengaruh variabel bebas terhadap variabel terikat sangat kuat.

\section{ANOVA (Analysis Of Variance)}

Anova digunakan untuk menguji kelayakan model regresi dengan ketentuan angka probabilitas yang baik adalah lebih kecil dari 0,05.

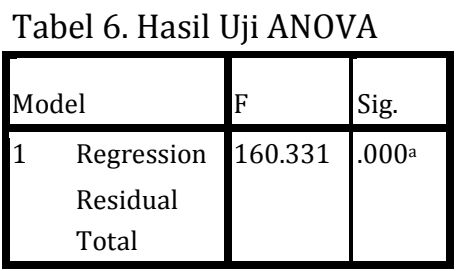

Dari hasil perhitungan uji ANOVA menunjukkan nilai $F$ sebesar 160.331 dengan tingkat signifikansi sebesar $0,000<0,05$ maka model regresi dikatakan layak untuk digunakan dalam memprediksi variabel Kinerja Karyawan.

Uji $\mathrm{t}$ digunakan untuk menguji signifikasi konstanta dan variabel Gaya Kepemimpinan. Dengan hipotesis (Widarjono, 2015):

- $\quad$ Ho = koefisien regresi tidak signifikan

- $\quad$ H1 = koefisien regresi signifikan

Keputusan

- Jika t hitung < t tabel maka Ho diterima

- Jika t hitung > t tabel maka Ho ditolak

Karena t hitung $(12,662)>t$ tabel $(1,687)$, maka Ho ditolak yang artinya koefisien regresi signifikan.

Untuk melihat kekuatan hubungan antar variabel penulis menggunakan uji korelasi rank spearman, dengan ketetapan:

1. Nilai koefisien korelasi sebesar 0,00 0,25 hubungan sangat lemah

2. Nilai koefisien korelasi sebesar 0,26 0,50 hubungan cukup

3. Nilai koefisien korelasi sebesar 0,51 0,75 hubungan kuat

4. Nilai koefisien korelasi sebesar 0,76 0,99 hubungan sangat kuat

5. Nilai koefisien korelasi sebesar 1,00 hubungan sempurna

Melihat hasil koefisien sebesar 0,851** maka tingkat kekuatan hubungan antara variabel gaya kepemimpinan dengan variabel kinerja karyawan sangat kuat. Arah hubungannya positif dengan nilai signifikan sebesar 0,000 . 


\section{Uji Heteroskedastisitas}

Uji heterokedasitas digunakan untuk mengetahui ada tidaknya kesamaan varian dari residual untuk semua pengamatan pada model regresi. Peneliti melakukan pengujian menggunakan uji rank spearman yang hasilnya dapat dilihat pada tabel di bawah ini:

Tabel 8. Hasil Uji Spearman

\begin{tabular}{|lll|r|r|}
\hline & & \multicolumn{1}{|c|}{$X$} & \multicolumn{1}{c|}{$Y$} \\
\hline Spearman's tho & $X$ & Correlation Coefficient & 1.000 & $.851^{\prime \prime}$ \\
& & & & .000 \\
& & & & 50 \\
& & & 50 \\
\cline { 2 - 4 } & $Y \quad$ Correlation Coefficient & $.851^{\prime \prime}$ & 1.000 \\
& Sig. (1-tailed) & .000 & \\
& $N$ & 50 & 50 \\
\hline
\end{tabular}

Dari tabel hasil uji heterokedasitas dapat disimpulkan, bahwa nilai signifikansi lebih dari 0,05 maka dapat dikatakan bahwa tidak terjadi masalah heterokedasitas.

\section{KESIMPULAN}

Dari hasil penelitian strategi membangun kedekatan antara pimpinan dan bawahan memberi dampak positif. Dengan memberikan contoh dari pola pemikiran seorang pemimpin dalam memberikan solusi dan arahan kepada bawahan dapat menciptakan komunikasi yang baik, karyawan dapat menyelesaikan pekerjaan sesuai yang diharapkan. Hal ini dibuktikan dari hasil olah data yang penulis lakukan melalui analisis data dengan melalui beberapa tahap pengujian maka dapat ditarik kesimpulan bahwa terdapat hubungan yang signifikan antara gaya kepemimpinan terhadap kinerja pegawai pada PT. Indonesia Super Holiday sebesar 0,877 dan termasuk dalam katagori sangat kuat setelah di hitung dengan menggunakan rumus koefisien korelasi.

Tabel 9. Corelation

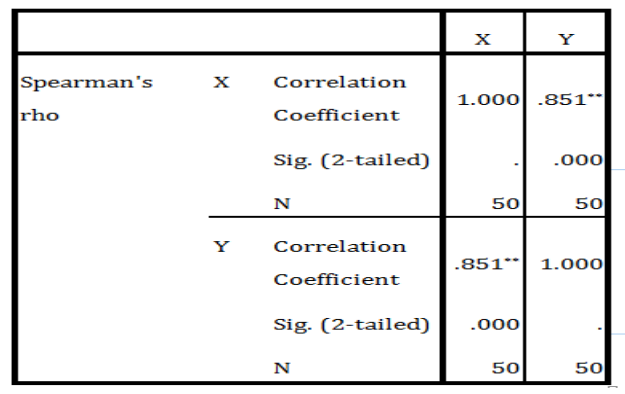

Penilaian yang objektif dari pimpinan kepada bawahan, memperkuat persepsi bahwa pengalaman seorang pimpinan memberikan perbedaan dengan yang kurang pengalaman. Pendidikan seorang pimpinan harus diserati jiwa kepemimpinan yang baik sehingga memberi dampak positif, semangat bawahan dalam bekerja dapat terpacu.

Berdasarkan dari hasil perhitungan diperoleh persentasi $\mathrm{R}$ sebesar $77,0 \%$ dan nilai adjusted $\mathrm{R}$ square sebesar 0,765 yang menunjukkan bahwa pengaruh gaya kepemimpinan terhadap kinerja karyawan terikat sangat kuat.

Berdasarkan perhitungan analisis regresi linear sederhana diperoleh persamaan $\mathrm{Y}=0,638+$ $0,809 x$ yang menunjukkan bahwa dengan gaya kepemimpinan yang baik, maka kinerja karyawan sebesar 0,638 dan jika X naik 1 (satu) atau gaya kepemimpinan dinaikkan sebesar 1 (satu) maka akan menaikkan kinerja karyawan sebesar 0,809 .

Melalui TAM menuntut penulis untuk melakukan beberapa pengujian sehingga anallisa keterkaitan antar variabel bisa diteliti dengan baik dan cermat. Sehingga seorang pemimpin bisa menerapkan pada perusahannya. Dengan Dengan pembuktian keterikatan antar variabel diharapkan bisa terus terjaga dan meningkatkan mutu dari seorang pemimpin. Penambahan indikator pengaruh perlu ditambahkan pada penelitian berikutnya dengan metode berbeda, sehingga bisa menambah persepsi faktor-faktor yang mempengaruhi kinerja karyawan, mengingat penelitian yang penulis lakukan saat ini melihat hanya dari gaya kepemimpinan.

\section{REFERENSI}

Davis, F. D. (1986). A Technology Acceptance Model For Empirically Testing New End-User Information Systems: Theory and Result. Massachusetts Institue of Technology.

Eva JR, T. (2015). Pengaruh Kepemimpinanterhadap Kinerja Pegawai Pada Kantor Sub.Dolog Wil.Iv Padangsidimpuan(Studi Padakantor Sub.Dolog Wil.Iv Padangsidimpuan). JAP, 3(2088-527x), 79-93.

Hamsinah, Sjahruddin, H., \& Gani, M. (2017). Pengaruh Gaya Kepemimpinan Dan Stres Kerja Terhadap Kepuasan Kerja Karyawan. Organisasi Dan Manajemen, (2), 62-77.

Mulyadi, D. (2015). Perilaku Organisasi dan Kepemimpinan Pelayanan (Pertama). Bandung: Alfabeta.

Priyatno, D. (2012). CARA KILAT BELAJAR Analisis Data dengan SPSS 20. (B. Rini W, Ed.). Andi Offset.

Riani, A. L. (2013). Manajemen Sumber Daya Manusia Masa Kini. Yogyakarta: Graha Ilmu. 
Stephen P. Robbins, S., \& Judge, T. A. (2015). Perilaku Organisasi Edisi 16. Jakarta: Salemba Empat.

Surpiyanto. (2012). Faktor-faktor yang mempengaruhi produktifitas kerja studi pada karyawan bagian produksi PT. Nusantara Building Industri. Manjemen, 1, 1.

Utami, S. (2017). Kajian Customer Information System: Studi Kasus Pada PT. Indonesia Super Holiday. IJSE - Indonesian Journal on Software Engineering, 3(2), 32-35.
Widarjono, A. (2015). STATISTIKA TERAPAN Dengan Excel \& SPSS (Pertama). Yogyakarta: UPP STIM YKPN.

Wijaya, S. W. (2006). Kajian Teoritis Technology Acceptance Model Sebagai Model Pendekatan Untuk Menentukan Strategi Mendororng Kemauan Pengguna Dalam Menggunakan Teknologi Informasi dan Komunikasi. Prosiding Konferensi Nasional Sistem Informasi. Yogyakarta. 